\title{
Foreign bodies in the ears causing complications and requiring hospitalization in children 0-14 age: Results from the ESFBI study
}

\author{
Dario Gregori ${ }^{\mathrm{a}, *}$, Bruno Morra ${ }^{\mathrm{d}}$, Paola Berchialla ${ }^{\mathrm{a}}$, Lorenzo Salerni ${ }^{\mathrm{b}}$, Cecilia Scarinzi ${ }^{\mathrm{c}}$, \\ Silvia Snidero ${ }^{\mathrm{c}}$, Roberto Corradetti ${ }^{\mathrm{c}}$, Desiderio Passali ${ }^{\mathrm{b}}$ \\ the ESFBI Study Group \\ ${ }^{a}$ Department of Public Health and Microbiology, University of Torino, Italy \\ ${ }^{\mathrm{b}}$ ENT Department, University of Siena, Italy \\ ${ }^{\mathrm{c}}$ Department of Statistics and Applied Mathematics, University of Torino, Italy \\ ${ }^{\mathrm{d}}$ ENT Department, San Giovanni Battista Hospital Torino, Italy
}

Received 18 August 2007; accepted 18 January 2008

Available online 2 June 2008

\begin{abstract}
Objective: The occurrence of foreign bodies (FBs) in otorhinolaryngological practice is a common and serious problem among patients in paediatric age. The aim of this work is to characterize the risk of complications and prolonged hospitalization due to foreign bodies in ears in terms of the characteristics of the injured patients (age, gender), typology and features of the foreign bodies, the circumstances of the accident and the hospitalization's details.

Methods: A retrospective study in major hospitals of 19 European countries was realized on children aged 0-14 with regard to the characteristics of the injured child and the FB, the circumstances of the accident and finally the hospitalization's details.

Results: Four hundred and ninety eight cases were reported with an injury due to insertion of a FB in the ear (ICD931). Complications were observed in $65(13.05 \%)$ children. Complications were lesion of auricular canal, perforation of tympanic membrane, local inflammation, bleeding, pain and otitis. Hospitalization lasted in median 1 day. The $82 \%$ of hospitalized children are in the "day hospital" regimen. The spherical, rigid and inorganic FB caused hospitalization in $61 \%, 63 \%$ and $84 \%$ of cases, respectively.

Conclusion: Foreign body injuries in the ears are commonly encountered in clinical practice. The removal by non-ENT personnel can be associated to complications especially in children who have a variable level of cooperation.

Occasions for the injury were mostly playing in the absence of watchful caregivers. Since prevention is the most essential way to deal with FB injuries public education should be encouraged.

(C) 2008 Elsevier Ireland Ltd. All rights reserved.
\end{abstract}

Keywords: Foreign bodies; Ears; Case management; Emergency care; Injuries

\section{Introduction}

Foreign body (FB) insertion in external auditory canal $(\mathrm{EAC})$ is not uncommon in emergency medicine and it may result in significant morbidity [1]. This is particularly true in

\footnotetext{
* Corresponding author at: Department of Public Health and Microbiology, University of Torino, Via Santena 5bis, 10126 Torino, Italy.

Tel.: +39 0116705813; fax: +390112365813.

E-mail address: dario.gregori@unito.it (D. Gregori).
}

children because of the small anatomic size and delicate skin of EAC and the thinness of the tympanic membrane. EAC is full of sensitive innervations supplied by fibers derived by vagus (nerve of Arnold), by auricular-temporal branch of mandibular nerve (3rd branch of the trigeminal nerve) and by a small contingent of fibers derived by the facial nerve. The innervations explain the exquisite sensitivity of these structures and the severe pain that the attempts of removal can cause so that very often a general anaesthesia or at least sedation must be used especially in younger patients [2-4]. 
This issue has received renewed attention in the last years $[5,6]$, particularly in view of the aspects related to object removal, case management in the Emergency Department [7] and risk of complications [8].

The aim of this work is to characterize the risk of complications and prolonged hospitalization due to foreign bodies in ears in terms of the characteristics of the injured patients (age, gender), typology and features of the FBs, the circumstances of the accident and the hospitalization's details, as emerging from the ESFBI study.

\section{Materials and methods}

\subsection{Sample}

The European Survey on Foreign Bodies Injuries (ESFBI) study collected data on FB injuries in the upper aero-digestive tract in children aged 0-14, from 19 European hospitals (Austria, Belgium, Bulgaria, Croatia, Czech Republic, Denmark, Finland, Germany, Greece, Italy, Poland, Romania, Slovakia, Slovenia, Spain, Sweden, Swiss, Turkey and United Kingdom). Data on 2103 injuries occurred in the years 2000-2002 were identified by means of the International Classification of Diseases, Ninth Revision (ICD-9) codes listed on hospital discharge records. The current analysis was carried out on 498 FB injuries in the ears (ICD931).

\subsection{Case Report Form $(C R F)$}

Details on injuries were gathered through a standardized Case Report Form (CRF). It encompassed four main aspects of the FB injuries: the characteristics of the children (age, gender), the characteristics of the object (shape, consistency, and dimension), circumstances of injury (presence of parents, activity) and hospitalization's details (lasting, complications and removal details).

Objects were characterized by size, shape and consistency, according to the Rimmell's definition [9]. With regard to their shape they were assigned to one of the following four categories: spherical—e.g. ball, pebble; three-dimensional (3D)—e.g. pen cap; two-dimensional (2D)—e.g. sheet, cellophane; and 2D circle-e.g. coin. In addition three categories of consistency were considered: conforminge.g. balloon, elastic; semi-rigid—e.g. eraser; and rigid—e.g. coin.

With regard to the size, when the dimensions (expressed in millimeters) of the object were reported, the volume was calculated accordingly to the shape of the objects itself, e.g. for three-dimensional objects the volume of a parallelepiped was calculated by the length of the axis, for spherical objects the volume of a sphere was calculated by the diameter reported and finally for two-dimensional circle objects the volume was approximated by that one of a cylinder with height $1 \mathrm{~mm}^{3}$. Such volume measures represent how much space the smallest geometrical figure containing the irregular-shaped FB takes up.

The CRF dedicated five questions about the associations of FBs with other kind of objects, both at the time of the accident and when the product was purchased. These questions were recoded into a new variable for the purpose of highlighting the industrial problems about the different components of the products.

We considered five different categories where the objects could be: (i) not an industrial component, (ii) a piece of an object: the FB was a broken part of the product (e.g. a broken part of a pen, the wheel of a toy car, etc.), (iii) in co-presence with another object: when the objects were sold together like the cap with the pen, the marble with a board game, etc., (iv) a package or a part of a package of a product (e.g. the tinfoil containing a chocolate, a polystyrene ball, a piece of cardboard, etc.), (v) the inedible part of a FPCI (food product containing inedibles): stickers in crisps, toys in chocolate eggs, etc. Where the association was not specified we considered the non-food product like a single object and not an industrial component.

Costs were based on direct costs only and estimated on the basis of the Italian DRG system and expressed in Euro.

\subsection{Outcomes}

Two outcomes were identified: (i) complications and (ii) hospitalization.

Complications, sometimes due to the attempts of removing the FB, may range from severe and persisting pain, to bleeding from the external ear canal skin due to lacerations or abrasions, eardrum perforations (of different severity till to the complete destruction of the membrane and ossicular luxation) and secondary otitis media [10,11].

Hospitalization has been defined whether the child was admitted in the hospital for at least 1 day. The hospitalization is generally required if the removal is carried out with microsurgical technique under general anaesthesia.

\subsection{Statistical methods}

Descriptive statistics (absolute and relative number or median, I and III quartile according to the categorical or continuous variable characteristic, respectively) were calculated. The association between outcomes and FB types, dimensions and characteristics, co-presence, activity during the injury and the presence of adults was also assessed using unweighted odds ratios and the related 95\% confidence intervals. Analyses were performed by using Design and Hmisc libraries from R version 2.4 [12].

\section{Results}

No deaths were observed. FB extraction from EAC was mostly performed by micro-otoscopy and aural irrigation, although some other techniques were also applied (otomicro- 


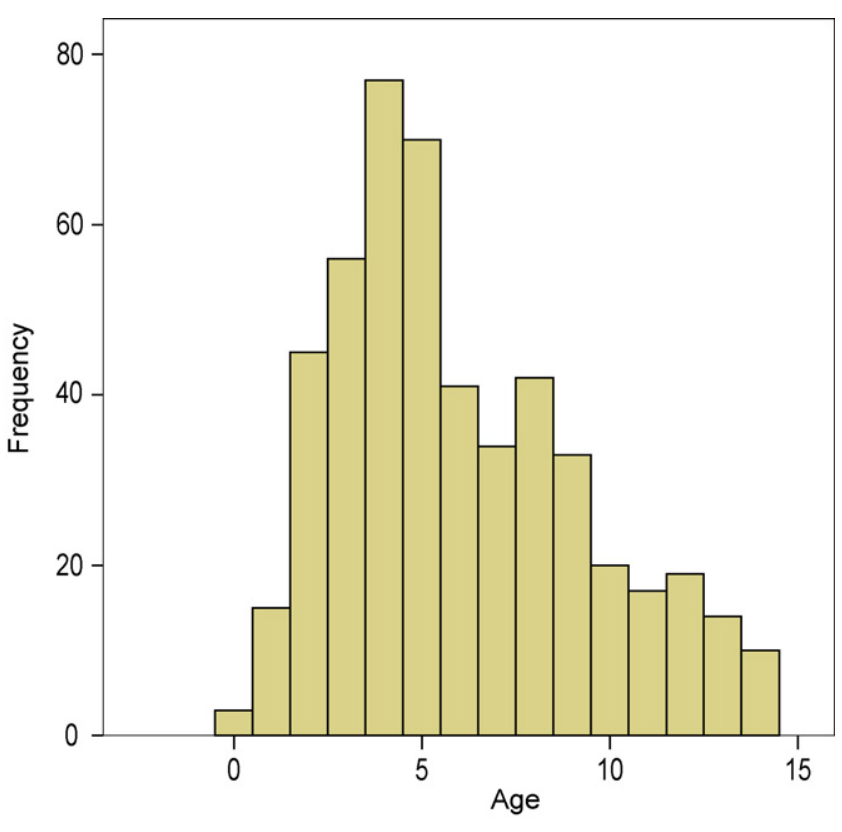

Fig. 1. Age distribution (in years) of the children.

scopy, extraction with forceps, siphoning and incision in the lobullus). Mean age of the children was 6 years (3.2 S.D.), with a greater likelihood of injury below 5 years (Fig. 1). The injuries occurred mostly in absence of an adult $(68 \%)$ when playing $(81 \%)$ or eating $(5 \%)$, but also in other occasions (during cleaning or writing). Out of the total of 498 injuries observed, 251 foreign bodies (62\%) were spherical objects and had rigid consistency (60\%). The type of the FB most frequently removed was balls, marbles and beads (27\%), pebbles, stones and grits (11\%), nuts (8\%), stationery (7\%). Four injuries were caused by the insertion of a battery. A special type of FB is represented by insects (2\%) (Table 1). In the $88 \%$ of cases, children were treated in by ENT personnel, and in the $12 \%$ of cases in the Emergency Department.

\subsection{Complications}

Complications were observed in $65(13 \%)$ children. Types of complications were lesion of auricular canal, perforation of tympanic membrane, local inflammation, bleeding, pain and otitis. A list of the complications observed and the actions and objects involved in the accident is presented in Table 1.

The major complication occurred in males $(57 \%)$. The median age of injured children with complication is 6 years old, only $9 \%$ of them are younger than 3 years (Tables 2 and 3 ).

\subsection{Hospitalization}

Hospitalization lasted in median 1 day, with only less than $25 \%$ of the patients having a longer stay. All the injured children were hospitalized in the ENT department.

The $82 \%$ of hospitalized children are in the "day hospital" regimen. The spherical, rigid and inorganic FB caused hospitalization in $61 \%, 63 \%$ and $84 \%$ of cases, respectively (Tables 2 and 3 ).

\section{Discussion}

The FB removal in the EAC is usually simple if it is inserted in the external cartilaginous portion of the EAC, while the removal becomes more difficult when the FB is lodged in a deeper situation like in the isthmus between cartilaginous and osseous portion or in the deeper and narrowest osseous portion of the EAC [4]. Even if the most common removal technique is aural irrigation by syringing with water (which is performed by a general practitioner or in peripherical ENT units) it is much safer to perform the removal in a specialized ENT unit with microsurgical technique under magnification and in a child under sedation

Table 1

Detailed list of actions and objects involved in the accident when a complication occurred

\begin{tabular}{ll}
\hline Complications & Objects and actions \\
\hline Otalgia & Playing with pebbles \\
Otitis & Playing with inorganics objects (pebbles; matbles; plastic toys) or using cotton wool \\
Perforation of tympanum & Insertion of seeds (while eating corns and grains); playing with a cotton wool \\
Infection & Playing with earrings \\
Inflammation of external ear & Playing with inorganics objects (balls, leads, piece of rubber, lead of pencils); using cotton wools \\
Superficial wound in the ear canal & Playing with inorganics objects (pebbles; pen caps); using cotton wool \\
Superficial bleeding & Playing with plastic objects batteries, pearls \\
One sided rhinitis & Playing with beads \\
Pain in the ear & Using earplug; playing with plastic balls; insects \\
Edema external canal & Playing with pebbles \\
Bloodshot of membrane tympany & Presence of an insect \\
Secretion and otodynia & Insertion of seeds; playing with a little ring or plastic objects \\
Hypoacusis and otodynia & Insect in the ear canal \\
Hypoacusis & Using cotton wool; playing with pen caps; insertion of pieces of vegetables and fruits \\
Otodynia & Playing with pen caps, beads, insertion of a piece of food \\
Pruritus & Piece of leaf \\
Secretion & Insertion of a piece of food \\
\hline All types of
\end{tabular}

All types of objects and actions actually occurred are listed for each observed complication. 
Table 2

Distribution of the overall sample and according to the presence of complications and the hospitalization (for at least 1 day)

\begin{tabular}{|c|c|c|c|c|c|c|c|c|c|}
\hline \multirow[t]{2}{*}{ Variable } & \multirow[t]{2}{*}{ Category } & \multirow[t]{2}{*}{$N$} & \multicolumn{3}{|c|}{ Presence of Complications } & \multicolumn{3}{|l|}{ Hospitalization } & \multirow{2}{*}{$\begin{array}{l}\text { Overall sample } \\
(N=443)\end{array}$} \\
\hline & & & No $(N=378)$ & Yes $(N=65)$ & Test & No $(N=348)$ & Yes $(N=89)$ & Test & \\
\hline Gender & Female & 483 & $40 \%(147)$ & $43 \%(27)$ & $P=0.688$ & $39 \%(130)$ & $51 \%(44)$ & $P=0.0447$ & $41 \%(174)$ \\
\hline Age & & 496 & $3 / 5 / 8$ & $4 / 6 / 9$ & $P=0.00616$ & $4 / 5 / 8$ & $3 / 5 / 7$ & $P=0.0178$ & $4 / 5 / 8$ \\
\hline Age -class & $\geq 3$ years & 493 & $88 \%(328)$ & $91 \%(59)$ & $P=0.48$ & $89 \%(308)$ & $83 \%(73)$ & $P=0.121$ & $88 \%(387)$ \\
\hline \multirow[t]{3}{*}{ Foreign Body removal } & Endoscopy & 450 & $48 \%(182)$ & $29 \%(19)$ & $P<0.001$ & $56 \%(195)$ & $6 \%(5)$ & $P<0.001$ & $45 \%(201)$ \\
\hline & Surgery & & $23 \%(85)$ & $12 \%(8)$ & & $6 \%(20)$ & $75 \%(66)$ & & $21 \%(93)$ \\
\hline & Other & & $29 \%(110)$ & $58 \%(38)$ & & $38 \%(133)$ & $19 \%(17)$ & & $33 \%(148)$ \\
\hline Hospitalization & Yes & 437 & $20 \%(75)$ & $19 \%(12)$ & $P=0.749$ & & & & \\
\hline \multirow[t]{4}{*}{ Lasting class } & 1 day & 88 & $88 \%(65)$ & $67 \%(8)$ & $P=0.139$ & & & & \\
\hline & 2 days & & $7 \%(5)$ & $25 \%(3)$ & & & & & \\
\hline & 3 days & & $3 \%(2)$ & $0 \%(0)$ & & & & & \\
\hline & More than 3 days & & $3 \%(2)$ & $8 \%(1)$ & & & & & \\
\hline \multirow[t]{3}{*}{ Regime of hospitalization } & Ordinary & 251 & $5 \%(12)$ & $30 \%(6)$ & $P<0.001$ & & & & \\
\hline & Day Hospital & & $33 \%(74)$ & $30 \%(6)$ & & & & & \\
\hline & Emergency Service & & $62 \%(141)$ & $40 \%(8)$ & & & & & \\
\hline First accident & Yes & 442 & $97 \%(360)$ & $97 \%(61)$ & $P=0.928$ & $98 \%(334)$ & $95 \%(83)$ & $P=0.181$ & $97 \%(421)$ \\
\hline \multirow[t]{3}{*}{ How many accident } & 1 & 11 & $67 \%(6)$ & $100 \%(2)$ & $P=0.632$ & $83 \%(5)$ & $67 \%(2)$ & & $73 \%(8)$ \\
\hline & 2 & & $22 \%(2)$ & $0 \%(0)$ & & $17 \%(1)$ & $33 \%(1)$ & & $18 \%(2)$ \\
\hline & 3 & & $11 \%(1)$ & $0 \%(0)$ & & $0 \%(0)$ & $0 \%(0)$ & & $9 \%(1)$ \\
\hline \multirow[t]{5}{*}{ Type of transport for reach the hospital } & In ambulance & 438 & $1 \%(2)$ & $2 \%(1)$ & & $0 \%(1)$ & $2 \%(2)$ & & $1 \%(3)$ \\
\hline & By taxi or in a private car & & $66 \%(242)$ & $78 \%(50)$ & & $66 \%(222)$ & $81 \%(70)$ & & $68 \%(292)$ \\
\hline & By public transport & & $32 \%(117)$ & $16 \%(10)$ & & $32 \%(108)$ & $14 \%(12)$ & & $29 \%(127)$ \\
\hline & Walking & & $2 \%(6)$ & $5 \%(3)$ & & $2 \%(7)$ & $2 \%(2)$ & & $2 \%(9)$ \\
\hline & Other & & $0 \%(0)$ & $0 \%(0)$ & & $0 \%(0)$ & $0 \%(0)$ & & $0 \%(0)$ \\
\hline \multirow[t]{5}{*}{ Department that look first after the child } & ENT Dept & 451 & $60 \%(225)$ & $69 \%(45)$ & & $68 \%(236)$ & $44 \%(39)$ & & $61 \%(270)$ \\
\hline & Paediatrics & & $11 \%(42)$ & $15 \%(10)$ & & $12 \%(42)$ & $9 \%(8)$ & & $12 \%(52)$ \\
\hline & Reanimation & & $0 \%(0)$ & $0 \%(0)$ & & $0 \%(0)$ & $0 \%(0)$ & & $0 \%(0)$ \\
\hline & Accident Emergency & & $28 \%(106)$ & $15 \%(10)$ & & $20 \%(69)$ & $45 \%(40)$ & & $26 \%(116)$ \\
\hline & Other & & $1 \%(5)$ & $0 \%(0)$ & & $0 \%(1)$ & $2 \%(2)$ & & $1 \%(5)$ \\
\hline \multirow[t]{5}{*}{ Department that discharged the child } & ENT Dept & 439 & $86 \%(315)$ & $98 \%(64)$ & & $85 \%$ (286) & $100 \%(87)$ & & $88 \%$ (379) \\
\hline & Paediatrics & & $0 \%(0)$ & $0 \%(0)$ & & $0 \%(0)$ & $0 \%(0)$ & & $0 \%(0)$ \\
\hline & Reanimation & & $0 \%(0)$ & $0 \%(0)$ & & $0 \%(0)$ & $0 \%(0)$ & & $0 \%(0)$ \\
\hline & Accident Emergency & & $14 \%(51)$ & $2 \%(1)$ & & $15 \%(52)$ & $0 \%(0)$ & & $12 \%(52)$ \\
\hline & Other & & $0 \%(0)$ & $0 \%(0)$ & & $0 \%(0)$ & $0 \%(0)$ & & $0 \%(0)$ \\
\hline Cost & & 88 & $\begin{array}{l}362.55 / 362.55 / \\
362.55\end{array}$ & $\begin{array}{l}362.55 / 362.55 / \\
1058.22\end{array}$ & $P=0.00423$ & - & $\begin{array}{l}362.55 / 362.55 / \\
362.55\end{array}$ & & $\begin{array}{l}362.55 / 362.55 / \\
362.55\end{array}$ \\
\hline
\end{tabular}

Data are I quartile, median III quartile for continuous variables and percentages (absolute numbers). $P$-values are based on a $F$-test for continuous variables and on a Chi-square test for categorical variables. $N$ is the number of cases with no missing information for the given variable. 
Table 3

Distribution of the overall sample and according to the presence of complications and the hospitalization (for at least 1 day) with respect to the characteristics of the foreign body and the circumstances of the accident

\begin{tabular}{|c|c|c|c|c|c|c|c|c|c|c|}
\hline & & \multirow[t]{2}{*}{$N$} & \multicolumn{4}{|c|}{ Presence of complications } & \multicolumn{4}{|l|}{ Hospitalization } \\
\hline & & & No $(N=378)$ & Yes $(N=65)$ & OR & $P$-value & No $(N=348)$ & Yes $(N=89)$ & OR & $P$-value \\
\hline \multirow[t]{5}{*}{ Shape } & Spherical & 415 & $64 \%(226)$ & $45 \%(25)$ & Ref & & $61 \%(193)$ & $63 \%(52)$ & Ref & \\
\hline & $3 \mathrm{D}$ & & $15 \%(51)$ & $36 \%(20)$ & $3.55(1.83-6.87)$ & 0.002 & $14 \%(46)$ & $29 \%(24)$ & $0.52(0.29-0.92)$ & 0.0257 \\
\hline & $2 \mathrm{D}$ & & $7 \%(25)$ & $12 \%(7)$ & $2.53(0.99-6.44)$ & 0.0514 & $9 \%(28)$ & $4 \%(3)$ & $2.51(0.74-8.6)$ & 0.141 \\
\hline & 2D circle & & $5 \%(18)$ & $5 \%(3)$ & $1.51(0.41-5.47)$ & 0.533 & $6 \%(19)$ & $4 \%(3)$ & $1.71(0.49-5.99)$ & 0.402 \\
\hline & other & & $9 \%(31)$ & $2 \%(1)$ & $0.29(0.04-2.23)$ & 0.235 & $10 \%(32)$ & $1 \%(1)$ & $8.62(1.15-64.59)$ & 0.036 \\
\hline First dimension & & 255 & $4 / 5 / 7$ & $5 / 5 / 7$ & $1.15(0.88-1.49)$ & 0.311 & $5.00 / 6.00 / 8.00$ & $2.75 / 3.00 / 4.00$ & $12.66(5.75-27.89)$ & $<0.001$ \\
\hline Second dimension & & 68 & $2 / 3 / 5$ & $3 / 3 / 5$ & $0.93(0.60-1.46)$ & 0.768 & $3.00 / 3.50 / 5.00$ & $2.00 / 3.00 / 3.75$ & $2.54(0.89-7.28)$ & 0.089 \\
\hline Third dimension & & 47 & $2 / 3 / 4$ & $2 / 3 / 4$ & $1.05(0.45-2.47)$ & 0.903 & $2.00 / 3.00 / 4.00$ & $1.75 / 3.00 / 3.00$ & $2.86(1.01-8.12)$ & 0.0485 \\
\hline \multirow[t]{3}{*}{ Consistency } & Conforming & 444 & $17 \%(62)$ & $22 \%(14)$ & Ref & & $18 \%(63)$ & $14 \%(12)$ & Ref & \\
\hline & Semi-rigid & & $21 \%(77)$ & $18 \%(12)$ & $1.34(0.68-2.62)$ & 0.387 & $19 \%(67)$ & $23 \%(20)$ & $1.37(0.69-2.72)$ & 0.267 \\
\hline & Rigid & & $61 \%(225)$ & $58 \%(38)$ & $0.92(0.46-1.86)$ & 0.398 & $60 \%(207)$ & $63 \%(54)$ & $0.87(0.49-1.56)$ & 0.369 \\
\hline \multirow[t]{5}{*}{ Co-presence } & No & 485 & $82 \%(299)$ & $73 \%(47)$ & Ref & & $83 \%(283)$ & $67 \%(58)$ & Ref & \\
\hline & Part of another object & & $12 \%(44)$ & $19 \%(12)$ & $1.74(0.85-3.52)$ & 0.127 & $12 \%(40)$ & $19 \%(16)$ & $0.51(0.27-9.8)$ & 0.042 \\
\hline & Package & & $1 \%(4)$ & $2 \%(1)$ & $1.59(0.17-14.5)$ & 0.681 & $0 \%(0)$ & $6 \%(5)$ & - & 0.758 \\
\hline & Different objects & & $5 \%(18)$ & $6 \%(4)$ & $1.41(0.46-4.36)$ & 0.546 & $4 \%(15)$ & $8 \%(7)$ & $0.44(0.17-1.12)$ & 0.086 \\
\hline & FPCI & & $0 \%(1)$ & $0 \%(0)$ & - & 0.83 & $0 \%(1)$ & $0 \%(0)$ & - & 0.897 \\
\hline Volume & & 212 & $30.00 / 65.41 / 179.50$ & $34.12 / 65.41 / 133.26$ & $0.95(0.71-1.27)$ & 0.741 & $33.49 / 80.00 / 267.94$ & $5.54 / 24 / 33.49$ & $45.52(9.74-212.78)$ & $<0.001$ \\
\hline Adult presence & Yes & 392 & $32 \%(106)$ & $31 \%(18)$ & $0.94(0.52-1.72)$ & 0.847 & $32 \%(96)$ & $32 \%(26)$ & $1.01(0.60-1.71)$ & 0.96 \\
\hline \multirow[t]{3}{*}{ Activity before accident } & Eating & 433 & $5 \%(18)$ & $6 \%(4)$ & Ref & & $6 \%(20)$ & $2 \%(2)$ & Ref & \\
\hline & Playing & & $81 \%(294)$ & $78 \%(49)$ & $1.33(0.43-4.11)$ & 0.616 & $78 \%(262)$ & $88 \%(72)$ & $2.75(0.63-12.03)$ & 0.179 \\
\hline & Other & & $14 \%(51)$ & $16 \%(10)$ & $1.18(0.56-2.47)$ & 0.847 & $16 \%(55)$ & $10 \%(8)$ & $1.89(0.86-4.15)$ & 0.652 \\
\hline \multirow[t]{2}{*}{ FB organic } & No & 498 & $74 \%(280)$ & $63 \%(41)$ & Ref & & $70 \%(243)$ & $84 \%(75)$ & Ref & \\
\hline & Yes & & $23 \%(88)$ & $35 \%(23)$ & $1.78(1.02-3.14)$ & 0.041 & $28 \%(97)$ & $13 \%(12)$ & $2.49(1.30-4.79)$ & 0.006 \\
\hline \multirow[t]{17}{*}{ FB type } & Balls, marbles and beads & 487 & $30 \%(112)$ & $9 \%(6)$ & Ref & & $26 \%(87)$ & $29 \%(25)$ & Ref & \\
\hline & Batteries & & $1 \%(3)$ & $2 \%(1)$ & $6.22(0.56-69.1)$ & 0.137 & $1 \%(2)$ & $2 \%(2)$ & $0.29(0.04-2.14)$ & 0.224 \\
\hline & Buttons & & $0 \%(0)$ & $0 \%(0)$ & & & $0 \%(0)$ & $0 \%(0)$ & & \\
\hline & Coins & & $0 \%(1)$ & $0 \%(0)$ & - & 0.926 & $0 \%(1)$ & $0 \%(0)$ & - & 0.850 \\
\hline & Foils and cellophane & & $1 \%(2)$ & $0 \%(0)$ & - & 0.896 & $0 \%(1)$ & $1 \%(1)$ & $0.29(0.02-4.76)$ & 0.384 \\
\hline & Food & & $2 \%(9)$ & $6 \%(4)$ & $8.30(1.97-34.87)$ & 0.004 & $4 \%(12)$ & $1 \%(1)$ & $3.45(0.43-27.8)$ & 0.245 \\
\hline & Jewelers & & $3 \%(12)$ & $6 \%(4)$ & $6.22(1.54-25.19)$ & 0.010 & $3 \%(10)$ & $7 \%(6)$ & $0.48(0.16-1.45)$ & 0.192 \\
\hline & $\begin{array}{l}\text { Nuts, seeds, berries, peas, } \\
\text { corns and beans }\end{array}$ & & $9 \%(33)$ & $5 \%(3)$ & $1.70(0.40-7.16)$ & 0.471 & $9 \%(32)$ & $3 \%(3)$ & $3.07(0.87-10.8)$ & 0.083 \\
\hline & Other inorganics & & $10 \%(36)$ & $14 \%(9)$ & $4.67(1.55-14.01)$ & 0.006 & $9 \%(32)$ & $16 \%(14)$ & $0.66(0.30-1.42)$ & 0.284 \\
\hline & Other organics & & $8 \%(30)$ & $23 \%(15)$ & $9.33(3.34-26.1)$ & 0.000 & $12 \%(40)$ & $6 \%(5)$ & $2.30(0.82-6.44)$ & 0.113 \\
\hline & Paper & & $4 \%(16)$ & $2 \%(1)$ & $1.17(0.13-10.3)$ & 0.890 & $4 \%(13)$ & $3 \%(3)$ & $1.25(0.33-4.72)$ & 0.747 \\
\hline & Pearls & & $7 \%(24)$ & $5 \%(3)$ & $2.33(0.54-9.99)$ & 0.254 & $7 \%(23)$ & $5 \%(4)$ & $1.65(0.52-5.22)$ & 0.393 \\
\hline & Pebbles, stones and grit & & $11 \%(40)$ & $9 \%(6)$ & $2.80(0.85-9.18)$ & 0.089 & $11 \%(37)$ & $10 \%(9)$ & $1.18(0.50-2.77)$ & 0.702 \\
\hline & Pins, screws, needles and nails & & $1 \%(3)$ & $0 \%(0)$ & - & 0.872 & $1 \%(3)$ & $2 \%(2)$ & $0.43-0.07-2.72)$ & 0.371 \\
\hline & Plastic & & $2 \%(8)$ & $5 \%(3)$ & $7.00(1.47-33.3)$ & 0.015 & $3 \%(10)$ & $1 \%(1)$ & $2.87(0.35-23.5)$ & 0.325 \\
\hline & Stationery & & $6 \%(23)$ & $12 \%(8)$ & $6.49(2.06-20.5)$ & 0.001 & $7 \%(23)$ & $8 \%(7)$ & $0.94(0.36-2.46)$ & 0.906 \\
\hline & Toys & & $4 \%(15)$ & $2 \%(1)$ & $1.24(0.14-11.0)$ & 0.844 & $4 \%(13)$ & $5 \%(4)$ & $0.93(0.28-3.12)$ & 0.912 \\
\hline
\end{tabular}

Data are I quartile, median III quartile for continuous variables and percentages (absolute numbers). Odds Ratio of complications and of hospitalization with the $95 \%$ confidence intervals is presented. $P$-values are also presented. $N$ is the number of cases with no missing information for the given variable. 
or a brief general anaesthesia. The microscope gives a magnified direct vision of the EAC and instruments like angle hook, cerumen loop, Frazier tip suction, alligator forceps and Hartman forceps can be used for a safe and complete FB removal.

Diagnosis of FB in EAC is generally easily conducted by otoscopy or micro-otoscopy while sequelae or complications could be diagnosed only after the FB removal. If hearing loss persisted after the removal a standard audiometric evaluation can be performed in children older than 4 , while in younger and not-cooperative children objective audiometry or behavioural audiometry is needed to diagnose the entity and nature of hearing loss. Moreover if an ossicular lesion is suspected, a high resolution CT scan can be performed as soon as the hemotympanum is reabsorbed.

The data analysis clearly shows that the most offending items are the rigid three-dimensional items. Object with sharp irregular edges can easily cause lacerations of the EAC skin and tympanic membrane perforation. In this case the removal in local or general anaesthesia under the microscopic vision is mandatory. Circular and smooth objects are less commonly cause of complications even if in current practice the use of a forceps can push the FB into a deeper situation along the EAC thus making more difficult its subsequent extraction; the use of aspiration even if its noise can be frightening to a little child - is less dangerous.

The organic FB, when impacted into the ear can often cause complications since - due to their hygroscopicity - the humid environment of the deep portion of the EAC determines the increase of the FB volume. So the delicate skin of the EAC undergoes maceration and bacterial or mycotic superinfection and can cause earache, ear fullness and otorrhea. The more the skin of the EAC is inflamed the more the attempts of FB's removal becomes painful and can cause bleeding which obscures the view: in these cases general anaesthesia and removal under microscopic magnification are recommended. It is fairly exceptional that a retroauricular approach must to be necessary for removing a very large and firmly impacted ancient FB.

Finally, even if a disk battery is a rare FB in the ear, and indeed were observed in only four cases, however it represents a serious emergency due to the leakage of alkaline corrosive substances that can cause a skin necrosis in short time: a prompt removal is warranted and it is mandatory not to use irrigation since it can increase the risk of electrolytic processes with ensuing some lesions.

\subsection{Final remarks}

Foreign body injuries in the ears are commonly encountered in clinical practice. The removal by nonENT personnel can be associated to complications especially in children who have a variable level of cooperation hence it should be discouraged.
Occasions for the injury were mostly playing in the absence of watchful caregivers. Since prevention is the most essential way to deal with FB injuries public education should be encouraged.

List of ESFBI group members omitted for blind reviewing.

\section{The ESFBI Study Group Coordinating Center}

Prof. Roberto Corradetti, University of Torino, Italy. Prof. Dario Gregori, University of Torino, Italy. Prof. Desiderio Passali, University of Siena, Italy. Dr Silvia Snidero, University of Torino, Italy.

\section{Austria}

Prof. Albegger Klaus, Head of the ENT-Department, Salzburg, Austria.

Dr. Huttegger Isidor, Universitätsklinik für Kinder- und Jugendheilkunde, Salzburg, Austria.

Dr. Schulz Gernot, Universitätsklinik für Kinder- und Jugendheilkunde, Salzburg, Austria.

Dr. Bauer Jan, Universitätsklinik für Kinder- und Jugendheilkunde, Salzburg, Austria.

\section{Belgium}

Prof. Bertrand Bernard, Cliniques Universitaires UCL de Mont-Godinne, ENT Dept., Yvoir, Belgium.

\section{Bulgaria}

Prof. Karchev Todor, University Hospital "Tzaritza Joanna", Sofia, Bulgaria.

Prof. Tzolov Tzolo, University Hospital "Tzaritza Joanna", Sofia, Bulgaria.

\section{Croatia}

Prof. Mladina Ranko, ORL Department, University Hospital Salata-KBC, Zagreb, Croatia.

Dr. Kovac Lana, ORL Department, University Hospital Salata-KBC, Zagreb, Croatia.

\section{Czech Republic}

Dr. Slapak Ivo, Pediatric ENT Department of Childrens University Hospital, Brno, Czech Republic.

\section{Denmark}

Prof. Tos Mirko, Gentofte University Hospital of Copenhagen, Hellerup, Denmark.

Prof. Per Caye-Thomasen, Gentofte University Hospital of Copenhagen, Hellerup, Denmark. 


\section{Finland}

Dr. Pitkäranta Anne, Helsinki University Central Hospital, Helsinki, Finland.

\section{Germany}

Prof. Jahnke Volker, Charitè Campus Virchow Klinikum, Berlin, Germany.

Dr. Göktas Önder, Charitè Campus Virchow - Klinikum, Berlin, Germany.

\section{Greece}

Prof. Nikola Simasko, Democritus University of Thrace, Ent Department, Alexandrupolis, Greece.

Dr. Chroni Matilda, Agia Sophia Children Hospital, Ent Department, Athens, Greece.

Dr. Dr Ioannis Christopoulos, Agia Sophia Children Hospital, Ent Department, Athens, Greece.

\section{Italy}

Prof. Desiderio Passàli, Dept. of Otorhinolaryngolgy, University of Siena, Italy.

Prof. Luisa Bellussi, Dept. of Otorhinolaryngolgy, University of Siena, Italy.

Dr. Giulio Cesare Passàli, Dept. of Otorhinolaryngolgy, University of Siena, Italy.

Dr. Francesco Passàli, Dept. of Otorhinolaryngolgy, University of Siena, Italy.

Dr. Valerio Damiani, Dept. of Otorhinolaryngolgy, University of Siena, Italy.

\section{Poland}

Prof. Chmielik Mieczysław, Department of Paediatric Otorhinolaryngology, The Medical University of Warsaw, Poland.

\section{Romania}

Prof. Sarafoleanu Dorin, Clinica ORL, Sfanta Maria Hospital, Bucharest, Romania.

Dr. Sarafoleanu Codrut, Clinica ORL, "Sfanta Maria Hospital", Bucharest, Romania.

Dr. Dan Cristian Gheorghe, Clinica ORL, "Spitalul de Copii Marie Curie”, Bucharest, Romania.

\section{Slovakia}

Prof. Jakubíková Janka, Pediatric Otolaryngology Department of Medical Faculty of Comenius University, Bratislava, Slovakia.

\section{Slovenia}

Prof. Žargi Miha, Department of Otorhinolaryngolgy and Cervicofacial Surgery, University Medical Centre, Ljubljana, Slovenia.

Dr. Grošelj Aleš, Department of Otorhinolaryngolgy and Cervicofacial Surgery, University Medical Centre, Ljubljana, Slovenia.

Dr. Matos Aleš, Department of Otorhinolaryngolgy and Cervicofacial Surgery, University Medical Centre, Ljubljana, Slovenia.

Spain

Prof. Rubio Lorenzo, Jefe de la Unidad ORL - Hospital Ruber International, Madrid Spain.

Dr. Cervera Javier, Hospital Niño Jesus, Madrid, Spain.

\section{Sweden}

Prof. Stierna Pontus, Karolinska University Hospital Huttinge, Stockholm, Sweden.

\section{Switzerland}

Prof. Pasche Philippe, Service ORL, Centre Hospitalier Universitaire Vaudois, Lausanne, Switzerland.

Dr. Cherif Ahmed, Service ORL, Centre Hospitalier Universitaire Vaudois, Lausanne, Switzerland.

Turkey

Prof. Önerci T. Metin, Hacettepe University, Dept. of Otorhinolaryngology, Ankara, Turkey.

Dr. Çiftçi Arbay Özden, Hacettepe University, Faculty of Medicine, Dept of Pediatric Surgery, Ankara, Turkey.

Dr. Doğan Riza, Hacettepe University, Faculty of Medicine, Dept of Cardiovascular Surgery, Ankara, Turkey.

\section{United Kingdom}

Prof. Graham John, Royal Free Hospital, London, UK. Dr. Rea Peter, Royal Free Hospital, London, UK.

Dr Obholtzer Rupert, Royal Free Hospital, London, UK.

\section{References}

[1] Balbani AP, Sanchez TG, Butugan O, Kii MA, Angelico Jr FV, Ikino $\mathrm{CM}$, et al. Ear and nose foreign body removal in children. Int J Pediatr Otorhinolaryngol 1998;46(1-2):37-42.

[2] Schulze SL, Kerschner J, Beste D. Pediatric external auditory canal foreign bodies: a review of 698 cases. Otolaryngol Head Neck Surg 2002;127(1):73-8.

[3] Ansley, Cunningham JFMJ. Treatment of aural foreign bodies in children. Pediatrics 1998;101(4 Pt 1):638-41. 
[4] Brown L, Denmark TK, Wittlake WA, Vargas EJ, Watson T, Crabb JW. Procedural sedation use in the ED: management of pediatric ear and nose foreign bodies. Am J Emerg Med 2004; 22(4):310-4.

[5] Fasunla AJ, Ogunleye OO, Ijaduola TG. Healthcare givers' skill and foreign bodies in the ears of children in the tropics. Int $\mathrm{J}$ Pediatr Otorhinolaryngol 2007;71(2):191-5.

[6] Jacob A, Morris TJ, Welling DB. Leaving a lasting impression: ear mold impressions as middle ear foreign bodies. Ann Otol Rhinol Laryngol 2006;115(12):912-6.

[7] DiMuzio Jr J, Deschler DG. Emergency department management of foreign bodies of the external ear canal in children. Otol Neurotol 2002;23(4):473-5.
[8] Botev B, Casale M, Salvinelli F, Hardy JF, Agro F. Removing a perforating foreign body in the head and neck: think before you act. J Emerg Med 2006;31(4):433-4.

[9] Rimell FL, Thome Jr A, Stool S, Reilly JS, Rider G, Stool D, et al. Characteristics of objects that cause choking in children. J Am Med Assoc 1996;274(22):1763-6.

[10] Harris KC, Conley SF, Kerschner JE. Foreign body granuloma of the external auditory canal. Pediatrics 2004;113(4):e371-3.

[11] Marin, Trainor JRJL. Foreign body removal from the external auditory canal in a pediatric emergency department. Pediatr Emerg Care 2006;22(9):630-4.

[12] R Development Core Team, R: A language and environment for statistical computing. 2005: Vienna, Austria. 